\title{
Recent dyslipidemia guidelines for patients with diabetes mellitus
}

\section{Eun-Jung Rhee}

Department of Endocrinology and Metabolism, Kangbuk Samsung Hospital, Sungkyunkwan University School of Medicine, Seoul, Korea

Received: June 30, 2020

Revised: August 14, 2020

Accepted: August 17, 2020

Corresponding author:

Eun-Jung Rhee

Department of Endocrinology

and Metabolism, Kangbuk

Samsung Hospital,

Sungkyunkwan University

School of Medicine, 29

Saemunan-ro, Jongno-gu,

Seoul 03181, Korea

Tel: +82-2-2001-2485

E-mail: hongsiri@hanmail.net

\section{ABSTRACT}

Treatment of diabetic dyslipidemia is important for the prevention of cardiovascular diseases in patients with diabetes. Although glucose control is the main target in patients with diabetes mellitus (DM) to prevent diabetic complications, multifactorial interventions are absolutely important to reduce the risk of cardiovascular diseases. Recent joint guidelines from the European Society of Cardiology and European Society for the Study of Diabetes have recommended lower low-density lipoprotein cholesterol (LDL-C) targets for patients with DM and included DM duration in the stratification of risk groups for cardiovascular disease prevention, emphasizing higher cardiovascular risk in patients with DM. In addition, the American Heart Association/American College of Cardiology guidelines were revised so that the LDL-C cutoff appeared in the guidelines for high risk groups and for changes in treatment options. The Korean Diabetes Association also released new treatment guidelines for patients with DM and adopted recent changes from other guidelines with respect to dyslipidemia control. In this review, I examined recent updates in the guidelines for dyslipidemia treatment for patients with DM.

Keywords: Diabetes mellitus; Dyslipidemias; Guideline
This is an Open Access article distributed under the terms of the Creative Commons Attribution Non-Commercial License (https:// creativecommons.org/licenses/ by-nc/4.0/).

\section{INTRODUCTION}

Diabetes mellitus (DM) is a chronic disease with high mortality and associated risks for cardiovascular diseases due to various vascular complications. Because the mortality rate due to cardiovascular diseases in patients with DM is two to four times higher than that in patients without DM, it is very important to control relevant risk factors including blood pressure, dyslipidemia, body weight, and smoking, in addition to blood glucose levels [1]. The Steno-2 study reported that the comprehensive management of various cardiovascular risk factors in diabetes patients could reduce the incidence of cardiovascular disease by up to $53 \%$; therefore, it is contextually very important to control these risk factors in this patient population [2].

Dyslipidemia is the most significant risk factor for atherosclerosis and cardiovascular diseases, regardless of the presence of diabetes. In the present review, I would like to discuss the risk status of dyslipidemia in patients with DM by reviewing recent studies that investigated treat- 
ments and the latest guidelines on dyslipidemia treatments in patients with $D M$.

\section{DYSLIPIDEMIA IN PATIENTS WITH DM}

According to the 2018 Diabetes Fact Sheet of the Korean Diabetes Association, hypercholesterolemia, defined as a total cholesterol level equal to or higher than $240 \mathrm{mg} / \mathrm{dL}$ or the use of lipid-lowering medication, was detected in $34.9 \%$ of Korean patients with DM aged $\geq 30$ years, while the control rate was $44.2 \%$ based on the results of the 2013 to 2016 Korean National Health and Nutrition Examination Survey [3]. The Dyslipidemia Fact Sheet of the Korean Society of Lipid and Arteriosclerosis revealed that the prevalence of dyslipidemia was approximately 2.3 times higher in DM patients than in non-diabetes subjects, even when dyslipidemia was more broadly defined [4]. In addition, the control rate was $44.2 \%$ when the target for low-density lipoprotein cholesterol (LDL-C) was set to $\leq 100 \mathrm{mg} / \mathrm{dL}$. Based on these findings, at least three of 10 adult Korean diabetes patients have hypercholesterolemia, and only four of 10 patients are able to control cholesterol levels to achieve target levels, suggesting that more active treatment is needed.

Numerous studies on cardiovascular disease prevention that investigate the effects of statins report results that could be summarized as "The lower, the better" [5]. The Adult Treatment Panel (ATP) I, which is regarded to be the first in the genealogy of dyslipidemia treatment guidelines, first proposed the targeting of LDL-C levels as a goal to prevent cardiovascular diseases [6]. Most subsequent guidelines have also proposed lowering LDL-C levels as the goal. Although dyslipidemia in individuals with type $2 \mathrm{DM}$ is characterized by high triglyceride, low high-density lipoprotein cholesterol (HDL-C), and high small-dense LDL levels, which leads to atherosclerosis, even in patients with DM, the risk of cardiovascular diseases decreases as LDL-C levels decrease [7].

In a sub-study from the United Kingdom Prospective Diabetes Study (UKPDS), the representative intervention study for the cardiovascular complications in type $2 \mathrm{DM}$, the most influential factor that affected the risk of coronary artery disease was the LDL-C level instead of the glycated hemoglobin, followed by HDL-C [8]. This result suggests that lowering LDL-C levels to the target level is the most important factor in the prevention of cardiovascular disease, even in patients with DM. Moreover, reducing LDL-C levels by $1 \mathrm{mmol} / \mathrm{L}$ can reduce coronary artery disease by $36 \%$.

According to the results of a recent analysis involving
271,174 patients with type 2 DM and 1,355,870 normoglycemic individuals registered in the Swedish National Diabetes registry, coronary artery disease exhibited a significantly linear correlation with LDL-C levels, unlike mortality or stroke, confirming the importance of lowering LDL-C levels to the recommended target values in the prevention of cardiovascular diseases [9].

\section{CLINICAL TRIALS ON DYSLIPIDEMIA IN PATIENTS WITH TYPE 2 DM}

Only a handful of primary prevention studies have examined the association between dyslipidemia treatment and cardiovascular diseases in patients with DM. The Collaborative Atorvastatin Diabetes Study (CARDS) [10] examined the time of onset of cardiovascular diseases as the primary efficacy endpoint by assigning 2,838 patients with type $2 \mathrm{DM}$ and with LDL-C levels $\leq 160 \mathrm{mg} / \mathrm{dL}$ without a history of coronary artery disease to either a 10-mg atorvastatin group or a placebo group. The study was terminated almost 2 years earlier than initially planned due to the significant effect of atorvastatin on cardiovascular disease prevention observed from the early stage of the study. In the group that received the 10$\mathrm{mg}$ atorvastatin, the incidence of myocardial infarction and stroke was $42 \%$ and $48 \%$ lower than those of the placebo group, respectively. The CARDS study has since been regarded as the most important study on the effect of statins and LDL-C lowering on the prevention of cardiovascular diseases in patients with DM in most guidelines.

The Cholesterol Treatment Trialists' Collaborators study compiled and analyzed clinical studies that investigated the effect of statins on the reduction of cardiovascular disease risk by reducing LDL-C levels in 18,686 patients with DM and 71,370 normal controls [11]. In the aforementioned study, a $1-\mathrm{mmol} / \mathrm{L}$ reduction in LDL-C level resulted in a $9 \%$ reduction in mortality and a $21 \%$ reduction in cardiovascular diseases. This result was similar to that observed in non-diabetic subjects and was independent of the presence or absence of existing cardiovascular diseases, demonstrating that a reduction in LDL-C levels in patients with DM through statin treatment is very important for the prevention of cardiovascular diseases.

While the latest guidelines have recommended only statin-based treatments, ezetimibe, a drug that inhibits cholesterol absorption from the small intestine, has been introduced to the market. Ezetimibe lowers cholesterol in the blood by blocking Niemann-Pick C1-like 1 proteins, which 
are responsible for absorbing cholesterol in the pericytes of the small intestine wall and in hepatocytes, thereby enabling cholesterol to be excreted in the stool [12]. The IMProved Reduction of Outcomes: Vytorin Efficacy International Trial (IMPROVE-IT), which examined the effect of ezetimibe in 18,144 patients with acute coronary syndrome, compared the incidence of cardiovascular diseases between a simvastatin 40 $\mathrm{mg}$ /ezetimibe $10 \mathrm{mg}$ group and a simvastatin $40 \mathrm{mg}$ group [13]. After 6 years of follow-up, the mean LDL-C concentration at the end of the study was $53.7 \mathrm{mg} / \mathrm{dL}$ in the simvastatin/ ezetimibe group and $69.5 \mathrm{mg} / \mathrm{dL}$ in the simvastatin group. This result demonstrated that the additional administration of ezetimibe was effective in patients who were receiving statin, since the incidence of cardiovascular diseases as the primary endpoint was reduced by $6 \%-$ a difference that was significant-in the group that additionally received ezetimibe. In addition, when the results of the 4,933 patients with DM included in the aforementioned study were analyzed separately, the effect of this drug was greater in patients with DM than in non-diabetic subjects [14]. The results of this study provided evidence to support the use of ezetimibe for the prevention of cardiovascular diseases in patients with $\mathrm{DM}$, and ezetimibe could be recommended in guidelines as a drug that can be administered after statin treatment.

The most significant change in dyslipidemia treatment in the latest guidelines is the recommendation for the use of a proprotein convertase subtilisin/kexin type 9 (PCSK9) inhibitor as a subsequent step after treatment with statin and ezetimibe $[15,16]$. PCSK9 is a member of the proprotein convertase family that binds to and degrades LDL receptors [17]. PCSK9 inhibitors inhibit the action of PCSK9 and lower LDL-C levels in the blood by promoting the expression of more LDL receptors on the surface of hepatocytes and other cells. In the latest PCSK9 inhibitor studies, such as the Further Cardiovascular Outcomes Research With PCSK9 Inhibition in Subjects With Elevated Risk (FOURIER) and ODYSSEY, the cardiovascular disease prevention effect of this drug was demonstrated in patients already on statins, as it additionally lowered the LDL-C level and the risk of cardiovascular diseases [18,19]. In addition, a recently published sub-analysis demonstrated better outcomes in patients with DM than in non-diabetic patients, and the addition of PCSK9 inhibitor was recommended with caution for patients with DM [20].

Unlike drugs that lower LDL-C levels, those that target triglyceride levels did not perform as expected. Fibrate, a representative triglyceride-lowering drug, did not demonstrate a significant cardiovascular disease prevention effect in the
Fenofibrate Intervention and Event Lowering in Diabetes study and the Action to Control Cardiovascular Risk in Diabetes (ACCORD) Lipid Trial in patients with DM, but demonstrated a borderline effect in the subgroup with high triglyceride and low HDL-C levels in the ACCORD study [21,22]. As a result, it was not strongly recommended in the guidelines. Omega-3, another triglyceride-lowering drug, also demonstrated no significant preventive effect; however, in the recently published Reduction of Cardiovascular Events with Icosapent Ethyl-Intervention Trial (REDUCE-IT) study, it demonstrated a significant preventive effect on cardiovascular diseases (25\%) when it was administered only as a component of eicosapent ethyl $2 \mathrm{~g}$ twice daily [23]. Furthermore, the results from a sub-analysis in patients with DM revealed significant preventive effects. However, it remains controversial because this is the result of only one study that investigated the effect of a special formula, the eicosapent ethyl component in quite high dosage of $2 \mathrm{~g}$ twice a day.

\section{DYSLIPIDEMIA TREATMENT GUIDELINES FROM INTERNATIONAL ASSOCIATIONS}

The history of the establishment of dyslipidemia guidelines closely follows that of the National Cholesterol Education Program expert panel on detection, evaluation, and treatment of high blood cholesterol in the National Cholesterol Education Program-Adult Treatment Panel (NCEP-ATP). ATP I, published in 1988, first emphasized that the prevention of cardiovascular diseases should focus on lowering LDL-C levels, and ATP II, released in 1993, recommended different treatments for risk groups divided according to risk factors and risk degrees [6,24]. ATP III, published in 2001, emphasized that the LDL-C concentration in the high-risk group should be $<100 \mathrm{mg} / \mathrm{dL}$, and DM was included in the 'coronary artery disease equivalent group' and was classified as a high-risk group [25]. In the updated ATP III guideline, metabolic syndrome was defined as having three among five risk factors, and diabetic patients with cardiovascular diseases were classified as a very high-risk group for which the target LDL-C level of $<70 \mathrm{mg} / \mathrm{dL}$ was considered [7].

After nearly 10 years of waiting for ATP IV, the American College of Cardiology/American Heart Association (ACC/AHA) guidelines were published in 2013 [26]. In these guidelines, the target level of LDL-C was eliminated. Additionally, patients between the ages of 40 and 75 years with cardiovascular diseases and an LDL-C level $\geq 190 \mathrm{mg} / \mathrm{dL}$, and patients between the ages of 40 to 75 years with DM and a cardiovascular disease risk level of at least $7.5 \%$ were included in the 
PRECISION AND FUTURE MEDICINE

Dyslipidemia guidelines for diabetes mellitus

Table 1. Recommendations for risk categories from various guidelines for patients with diabetes

\begin{tabular}{|c|c|c|c|c|}
\hline & $\begin{array}{l}\text { ACC/AHA/ADA } \\
\text { (2019) }\end{array}$ & $\begin{array}{c}\text { ESC } \\
(2019)\end{array}$ & $\begin{array}{l}\text { Korean Diabetes Association } \\
\qquad(2019)\end{array}$ & $\begin{array}{l}\text { Korean Society of Lipid } \\
\text { and Atherosclerosis } \\
\qquad(2018)\end{array}$ \\
\hline $\begin{array}{l}\text { Diabetes+multiple } \\
\text { risk factors }\end{array}$ & High risk & $\begin{array}{l}\text { Very high risk: target organ damage } \\
\text { three or more risk factors }{ }^{\mathrm{b})}, \text { T1DM } \\
\text { duration }>20 \text { years }\end{array}$ & $\begin{array}{l}\text { Very high risk: albuminuria, target } \\
\text { organ damage such as eGFR }<60 \\
\mathrm{~mL} / \mathrm{min} / 1.73 \mathrm{~m}^{2} \text {, major risk } \\
\text { factors }^{\mathrm{c}}\end{array}$ & $\begin{array}{l}\text { Very high risk: could } \\
\text { include target organ } \\
\text { damage }^{\text {a) }} \text { or major risk } \\
\text { factors }^{c)}\end{array}$ \\
\hline Diabetes+ASCVD & Very high risk & Very high risk & Very high risk & Very high risk \\
\hline
\end{tabular}

ACC/AHA/ADA, American College of Cardiology/American Heart Association/American Diabetes Association; ESC, European Society of Cardiology; T1DM, type 1 diabetes mellitus; eGFR, estimated glomerular filtration rate; ASCVD, atherosclerotic cardiovascular disease.

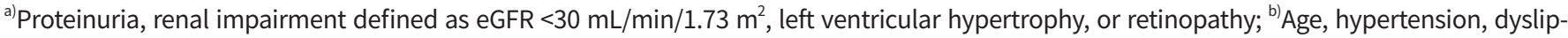
idemia, smoking, and obesity; ${ }^{\mathrm{c}}$ Age (men $\geq 45$ years, women $\geq 55$ years), family history of premature ASCVD, hypertension, smoking, and low high-density lipoprotein cholesterol level.

four 'statin benefit groups.' Those who fulfilled these criteria were recommended to use statins with at least moderate intensity, by classifying statins into three groups of high, moderate, and low intensity. However, these guidelines were not easily endorsed by many associations because they did not take into account ethnic differences, in that, most of the studies mentioned were conducted in Caucasian populations. Additionally, these guidelines were not easily endorsed because LDL-C target levels were eliminated from them, with virtually no mention of recommendations for non-statin treatments.

The European Society of Cardiology (ESC) guidelines, published in 2016, did not follow the 2013 ACC/AHA guidelines but used the existing risk group classification [27]. Diabetic patients with target organ damage were classified as an ultra-high-risk group, whereas those without target organ damage were classified as a high-risk group. Recommendations were made to adjust the LDL-C target value lower than 100 and $70 \mathrm{mg} / \mathrm{dL}$ for high-risk and very high-risk groups, respectively. The 2019 ESC guidelines, on diabetes in collaboration with European Association for the Study of Diabetes, published last year, categorized diabetic patients according to disease duration [28]. Patients with type 1 DM with a disease duration of $\geq 20$ years were classified as the very highrisk group and patients with type 2 DM for $>10$ years were classified as the high-risk group (Table 1). In addition, these guidelines recommended even lower LDL-C target goals in patients with DM: $55 \mathrm{mg} / \mathrm{dL}$ for the very high-risk group and
$<70 \mathrm{mg} / \mathrm{dL}$ for the high-risk group. This emphasizes that patients with DM are at a high cardiovascular risk (Table 2). Although LDL-C is the primary target, and the main treatment modality is statin, the administration of ezetimibe followed by PCSK9 inhibitors is recommended if the goal is not achieved or when side effects occur. Interestingly, for patients who exhibit persistently high triglyceride levels despite statin administration according to the previously reported results of the REDUCE-IT study, the administration of eicosapent ethyl $2 \mathrm{~g}$ twice daily is recommended, with a recommendation level of Ila [23].

The ACC/AHA guidelines revised in 2019 made several changes to the recommendations for primary prevention, such as suggesting a risk enhancing factor in patients with DM. These guidelines recommended the use of high-intensity statin when there are risk factors such as DM of long duration, albuminuria, estimated glomerular filtration rate (eGFR) $<60 \mathrm{~mL} / \mathrm{min} / 1.73$ $\mathrm{m}^{2}$, retinopathy, neuropathy, and ankle-brachial index $<0.9$ [15]. In addition, the LDL-C target level reappeared, which indicated that a subsequent treatment could be added if an LDL-C level of $70 \mathrm{mg} / \mathrm{dL}$ is not achieved despite appropriate statin administration. The American Diabetes Association guidelines recommend that the summary of details for patients with DM be taken from the 2013 and 2019 ACC/AHA guidelines (Table 1). Additionally, the primary recommended treatment is statin, followed by ezetimibe and PCSK9 inhibitors (Table 2).

The Korean Society of Lipid and Arteriosclerosis published the 4th edition of treatment guidelines. The history of these guidelines is quite similar to that of the ATP guidelines, with 
Table 2. Recommendations for treatment targets from various guidelines for patients with diabetes

\begin{tabular}{|c|c|c|c|c|}
\hline & ACC/AHA/ADA (2019) & ESC (2019) & $\begin{array}{l}\text { Korean } \\
\text { Diabetes } \\
\text { Association } \\
\text { (2019) }\end{array}$ & $\begin{array}{l}\text { Korean Society } \\
\text { of Lipid and } \\
\text { Atherosclerosis } \\
\qquad(2018)\end{array}$ \\
\hline Diabetes only & $\begin{array}{l}\text { Aged } 40-75 \text { years and }>75 \text { years without atherosclerotic } \\
\text { cardiovascular disease: moderate-intensity statin }\end{array}$ & $\begin{array}{l}\text { LDL-C level }<100 \mathrm{mg} / \mathrm{dL} \text { (mod- } \\
\text { erate) } \geq 50 \% \text { reduction from } \\
\text { baseline and LDL-C level }<70 \\
\mathrm{mg} / \mathrm{dL} \text { (high risk) }\end{array}$ & $\begin{array}{l}\text { LDL-C level } \\
<100 \mathrm{mg} / \mathrm{dL}\end{array}$ & $\begin{array}{l}\text { LDL-C level } \\
<100 \mathrm{mg} / \mathrm{dL}\end{array}$ \\
\hline $\begin{array}{l}\text { Diabetes+multiple } \\
\text { risk factors }\end{array}$ & $\begin{array}{l}\text { All ages with } 10 \text { years atherosclerotic cardiovascular } \\
\text { disease risk }>20 \% \text { : high-intensity statin therapy } \\
<40 \text { years with additional atherosclerotic cardiovascular } \\
\text { disease risk factors: moderate-intensity statin }\end{array}$ & $\begin{array}{l}\geq 50 \% \text { reduction from baseline } \\
\text { and } \mathrm{LDL}-\mathrm{C} \text { level }<55 \mathrm{mg} / \mathrm{dL} \\
\text { (very high risk) }\end{array}$ & $\begin{array}{l}\text { LDL-C level } \\
<70 \mathrm{mg} / \mathrm{dL}\end{array}$ & $\begin{array}{l}\text { LDL-C level } \\
<70 \mathrm{mg} / \mathrm{dL}\end{array}$ \\
\hline Diabetes+ASCVD & $\begin{array}{l}\text { All ages with diabetes and ASCVD: high-intensity statin } \\
\text { therapy } \\
\text { If LDL-C level is } \geq 70 \mathrm{mg} / \mathrm{dL} \text { on maximally } \\
\text { tolerated statin dose, additional LDL-lowering } \\
\text { therapy (such as ezetimibe or PCSK9 inhibitor). } \\
\text { Ezetimibe may be preferred due to lower cost. }\end{array}$ & $\begin{array}{l}\geq 50 \% \text { reduction from baseline } \\
\text { and } L D L-C \text { level }<55 \mathrm{mg} / \mathrm{dL}\end{array}$ & $\begin{array}{l}\text { LDL-C level } \\
<70 \mathrm{mg} / \mathrm{dL}\end{array}$ & $\begin{array}{l}\text { LDL-C level } \\
<70 \mathrm{mg} / \mathrm{dL}\end{array}$ \\
\hline
\end{tabular}

ACC/AHA/ADA, American College of Cardiology/American Heart Association/American Diabetes Association; ESC, European Society of Cardiology; LDL-C, low-density lipoprotein cholesterol; ASCVD, atherosclerotic cardiovascular disease; PCSK9, proprotein convertase subtilisin/kexin type 9.

the 1st edition published in 1996 [29]. In these guidelines, DM belongs to the high-risk group, and it can be elevated to the very high-risk group if accompanied by target organ damage or a significant cardiovascular disease risk factor (Table 1). In the guidelines, it is recommended that the LDL-C level be lowered to 100 and $70 \mathrm{mg} / \mathrm{dL}$ for the high-risk and the very high-risk groups, respectively (Table 2).

\section{KOREAN DIABETES ASSOCIATION TREATMENT GUIDELINES, 6TH EDITION}

Although many guidelines have been proposed, as described earlier, it is more convenient to refer to the guidelines of the Korean Diabetes Association, which is as follows [30]:

1. Serum lipid tests (total cholesterol, HDL-C, triglyceride, and LDL-C) should be performed at the time of DM diagnosis and at least once per year. Tests are conducted before and after 4 to 12 weeks of starting drug administration to assess response to drug and compliance (E, I).

2. In patients with DM and without cardiovascular disease, lower the LDL-C level to $<100 \mathrm{mg} / \mathrm{dL}$ (A, I).

3. In patients with DM and with cardiovascular disease, lower the LDL-C level to $<70 \mathrm{mg} / \mathrm{dL}(\mathrm{A}, \mathrm{I})$.

4. In patients with $\mathrm{DM}$, target organ damage, and conditions such as albuminuria and chronic kidney disease (eGFR $<60 \mathrm{~mL} / \mathrm{min} / 1.73 \mathrm{~m}^{2}$ ) or risk factors such as hyperten- sion, smoking, and/or family history of early-onset coronary artery disease, lower the LDL-C level to $<70 \mathrm{mg} / \mathrm{dL}$ (B, Ila).

5. The target goal is $<150 \mathrm{mg} / \mathrm{dL}$ for triglycerides or $>40$ $\mathrm{mg} / \mathrm{dL}$ in men and $>50 \mathrm{mg} / \mathrm{dL}$ in women for HDL-C. To this end, lifestyle modification should be actively recommended, and strict glucose control is recommended $(\mathrm{C}, \mathrm{I})$.

6. In patients with dyslipidemia, education for active life style modification is recommended (A, I).

7. In patients with DM and dyslipidemia, statins are used as the first-line treatment $(\mathrm{A}, \mathrm{I})$.

8. Consider the addition of ezetimibe or PCSK9 inhibitors if the LDL-C target is not achieved with the maximum tolerable dose of statin in patients with DM and with cardiovascular diseases. However, ezetimibe is preferred for financial reasons (B, Ila).

9. Addition of ezetimibe may be considered in patients with DM without cardiovascular diseases who do not achieve LDL-C target levels with the maximum tolerable dose of statin (C, Ilb).

In the 6th edition of the treatment guidelines of the Korean Diabetes Association, the strategies of drug treatment for dyslipidemia in patients with DM are illustrated in detail (Fig. 1). First, the presence of cardiovascular disease, target organ damage, or major risk factors for cardiovascular diseases should be assessed and the LDL-C target values should be set (Table 1). If 


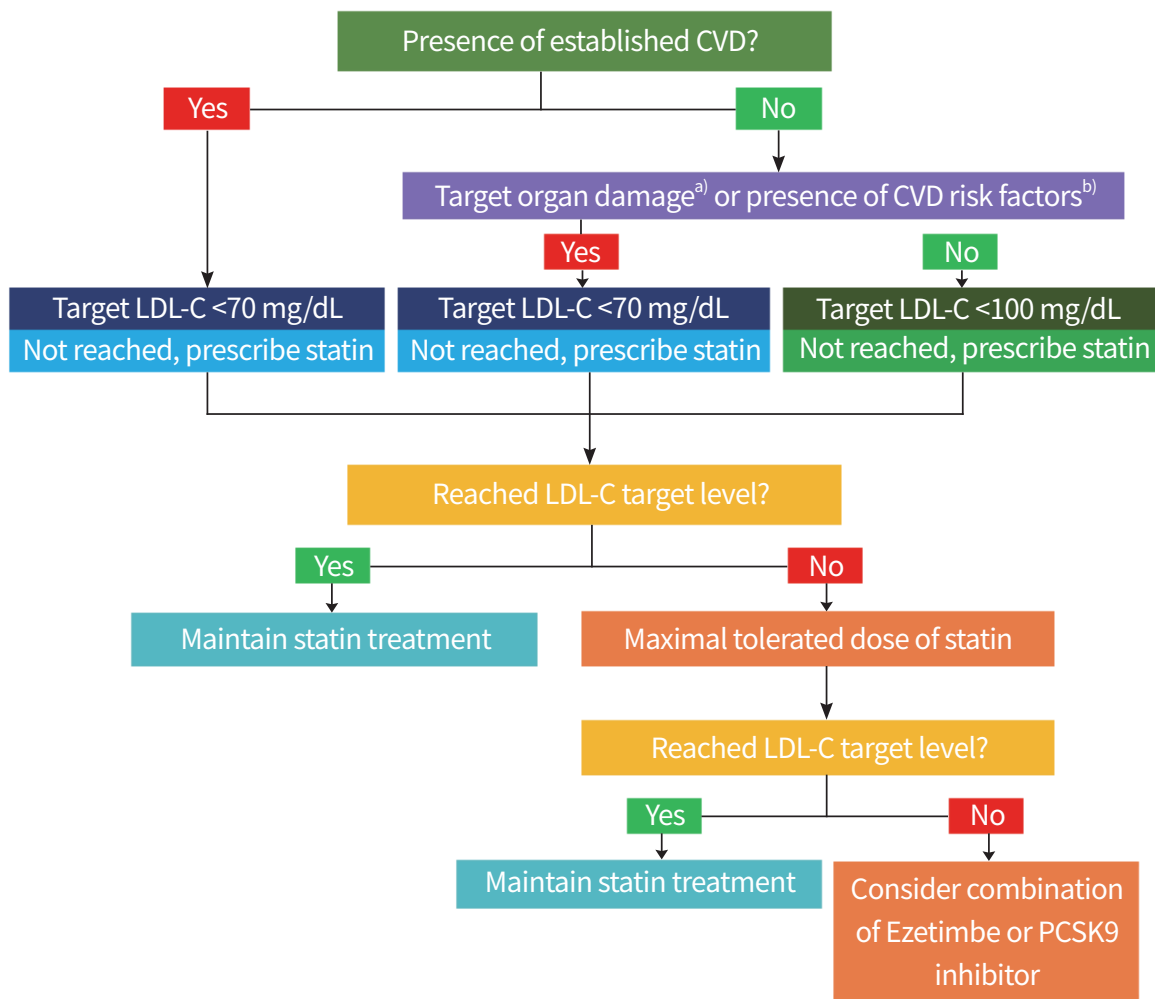

Fig. 1. Algorithm for management of dyslipidemia in patients with diabetes. Adapted from Korean Diabetes Association [30]. CVD, cardiovascular disease; LDL-C, low-density lipoprotein cholesterol; PCSK9, proprotein convertase subtilisin/kexin type 9. ${ }^{\text {a) }}$ Albuminuria or chronic kidney disease (estimated glomerular filtration rate $<60 \mathrm{~mL} / \mathrm{min} / 1.73 \mathrm{~m}^{2}$ ); b) Hypertension, smoking or family history of premature coronary artery disease.

the basal LDL-C level does not meet the target, statin administration is started first, and LDL-C test is performed 4 to 12 weeks after the start of administration to determine whether the target has been achieved and whether there are any side effects (Table 2). Maintain existing statin treatment if the target is achieved; otherwise, consider combining or replacing with other agents if the target is not achieved or if there are any side effects.

\section{CONCLUSION}

Tables 1, 2 summarize the content of this review. Although it may appear complicated, the recommended LDL-C target level for patients with DM is $<70$ and $<55 \mathrm{mg} / \mathrm{dL}$ in patients at a higher risk; however, there is little supportive evidence for this value. For treatment, statins may be considered first, followed by ezetimibe and, in rare cases, even PCSK9 inhibitors. In Korea, PCSK9 inhibitors has been covered by insurance since January 2020 in very high-risk group patients for CVD, heterozygous familial hypercholesterolemic patients and patients with statin intolerance. What is important is that the risk of cardiovascular diseases in patients with DM is high and, therefore, treatment of dyslipidemia in patients with DM is critical for the prevention and treatment of cardiovascular diseases. Considering that the risk of cardiovascular mortality remains high despite aggressive treatment possibly due to the fact that the control rate of dyslipidemia does not reach $100 \%$, it is very important to provide appropriate treatment to achieve target LDL-C levels after appropriate risk assessment.

\section{CONFLICTS OF INTEREST}

No potential conflict of interest relevant to this article was reported.

\section{ORCID}

Eun-Jung Rhee https://orcid.org/0000-0002-6108-7758

\section{AUTHOR CONTRIBUTIONS}

Conception or design: EJR. 
Acquisition, analysis, or interpretation of data: EJR.

Drafting the work or revising: EJR.

Final approval of the manuscript: EJR.

\section{REFERENCES}

1. Haffner SM, Lehto S, Ronnemaa T, Pyorala K, Laakso M. Mortality from coronary heart disease in subjects with type 2 diabetes and in nondiabetic subjects with and without prior myocardial infarction. N Engl J Med 1998; 339:229-34.

2. Gaede P, Vedel P, Larsen N, Jensen GV, Parving HH, Pedersen $\mathrm{O}$. Multifactorial intervention and cardiovascular disease in patients with type 2 diabetes. N Engl J Med 2003; 348:383-93.

3. Korean Diabetes Association. Diabetes fact sheet in Korea [Internet]. Seoul (KR): Korean Diabetes Association; c2011 [cited 2020 Aug 24]. Available from: https://www. diabetes.or.kr/pro/news/admin.php?mode=list\&category=A.

4. The Korean Society of Lipid and Atherosclerosis. Dyslipidemia fact sheet [Internet]. Seoul (KR): the Korean Society of Lipid and Atherosclerosis; 2020 [cited 2020 Aug 24]. Available from: https://www.lipid.or.kr/bbs/?code=fact_ sheet.

5. Opie LH, Gersh BJ, editors. Drugs for the heart. 8th ed. Philadelphia (PA): Elsevier; 2013. p. 411.

6. The Expert Panel. Report of the National Cholesterol Education Program Expert Panel on detection, evaluation, and treatment of high blood cholesterol in adults. Arch Intern Med 1988;148:36-69.

7. Grundy SM, Cleeman JI, Merz CN, Brewer HB Jr, Clark LT, Hunninghake DB, et al. Implications of recent clinical trials for the National Cholesterol Education Program Adult Treatment Panel III guidelines. Circulation 2004;110:22739.

8. Turner RC, Millns H, Neil HA, Stratton IM, Manley SE, Matthews DR, et al. Risk factors for coronary artery disease in non-insulin dependent diabetes mellitus: United Kingdom Prospective Diabetes Study (UKPDS: 23). BMJ 1998; 316:823-8.

9. Rawshani A, Rawshani A, Franzen S, Sattar N, Eliasson B, Svensson AM, et al. Risk factors, mortality, and cardiovascular outcomes in patients with type 2 diabetes. N Engl J Med 2018;379:633-44.

10. Colhoun HM, Betteridge DJ, Durrington PN, Hitman GA, Neil HA, Livingstone SJ, et al. Primary prevention of car- diovascular disease with atorvastatin in type 2 diabetes in the Collaborative Atorvastatin Diabetes Study (CARDS): multicentre randomised placebo-controlled trial. Lancet 2004;364:685-96.

11. Cholesterol Treatment Trialists' (CTT) Collaborators, Kearney PM, Blackwell L, Collins R, Keech A, Simes J, et al. Efficacy of cholesterol-lowering therapy in 18,686 people with diabetes in 14 randomised trials of statins: a meta-analysis. Lancet 2008;371:117-25.

12. Phan BA, Dayspring TD, Toth PP. Ezetimibe therapy: mechanism of action and clinical update. Vasc Health Risk Manag 2012;8:415-27.

13. Cannon CP, Blazing MA, Giugliano RP, McCagg A, White $J A$, Theroux $P$, et al. Ezetimibe added to statin therapy after acute coronary syndromes. N Engl J Med 2015;372: 2387-97.

14. Giugliano RP, Cannon CP, Blazing MA, Nicolau JC, Corbalan R, Spinar J, et al. Benefit of adding ezetimibe to statin therapy on cardiovascular outcomes and safety in patients with versus without diabetes mellitus: results from IMPROVE-IT (Improved Reduction of Outcomes: Vytorin Efficacy International Trial). Circulation 2018;137:157182.

15. Arnett DK, Blumenthal RS, Albert MA, Buroker AB, Goldberger ZD, Hahn EJ, et al. 2019 ACC/AHA guideline on the primary prevention of cardiovascular disease: executive summary: a report of the American College of Cardiology/American Heart Association Task Force on clinical practice guidelines. J Am Coll Cardiol 2019;74:1376-414.

16. Mach F, Baigent C, Catapano AL, Koskinas KC, Casula M, Badimon L, et al. 2019 ESC/EAS guidelines for the management of dyslipidaemias: lipid modification to reduce cardiovascular risk. Eur Heart J 2020;41:111-88.

17. Lagace TA. PCSK9 and LDLR degradation: regulatory mechanisms in circulation and in cells. Curr Opin Lipidol 2014; 25:387-93.

18. Sabatine MS, Giugliano RP, Keech AC, Honarpour N, Wiviott SD, Murphy SA, et al. Evolocumab and clinical outcomes in patients with cardiovascular disease. $\mathrm{N}$ Engl J Med 2017;376:1713-22.

19. Schwartz GG, Steg PG, Szarek M, Bhatt DL, Bittner VA, Diaz R, et al. Alirocumab and cardiovascular outcomes after acute coronary syndrome. N Engl J Med 2018;379:2097-107.

20. Sabatine MS, Leiter LA, Wiviott SD, Giugliano RP, Deedwania P, De Ferrari GM, et al. Cardiovascular safety and efficacy of the PCSK9 inhibitor evolocumab in patients with and without diabetes and the effect of evolocumab on 
glycaemia and risk of new-onset diabetes: a prespecified analysis of the FOURIER randomised controlled trial. Lancet Diabetes Endocrinol 2017;5:941-50.

21. Tonkin A, Hunt D, Voysey M, Kesaniemi A, Hamer A, Waites $\mathrm{J}$, et al. Effects of fenofibrate on cardiovascular events in patients with diabetes, with and without prior cardiovascular disease: the Fenofibrate Intervention and Event Lowering in Diabetes (FIELD) study. Am Heart J 2012;163: 508-14.

22. ACCORD Study Group, Ginsberg HN, Elam MB, Lovato LC, Crouse JR 3rd, Leiter LA, et al. Effects of combination lipid therapy in type 2 diabetes mellitus. N Engl J Med 2010; 362:1563-74.

23. Bhatt DL, Steg PG, Miller M, Brinton EA, Jacobson TA, Ketchum $\mathrm{SB}$, et al. Cardiovascular risk reduction with icosapent ethyl for hypertriglyceridemia. N Engl J Med 2019;380:11-22.

24. National Cholesterol Education Program. Second report of the expert panel on detection, evaluation, and treatment of high blood cholesterol in adults (Adult Treatment Panel II). Circulation 1994;89:1333-445.

25. National Cholesterol Education Program (NCEP) Expert Panel on Detection, Evaluation, and Treatment of High Blood Cholesterol in Adults (Adult Treatment Panel III). Third report of the National Cholesterol Education Program (NCEP) expert panel on detection, evaluation, and treatment of high blood cholesterol in adults (Adult Treatment Panel III) final report. Circulation 2002;106:3143-421.

26. Stone NJ, Robinson JG, Lichtenstein AH, Bairey Merz CN, Blum CB, Eckel RH, et al. 2013 ACC/AHA guideline on the treatment of blood cholesterol to reduce atherosclerotic cardiovascular risk in adults: a report of the American College of Cardiology/American Heart Association task force on practice guidelines. J Am Coll Cardiol 2014;63(25 Pt B):2889-934.

27. Catapano AL, Graham I, De Backer G, Wiklund O, Chapman MJ, Drexel H, et al. 2016 ESC/EAS guidelines for the management of dyslipidaemias. Eur Heart J 2016;37:29993058.

28. Cosentino F, Grant PJ, Aboyans V, Bailey CJ, Ceriello A, Delgado V, et al. 2019 ESC guidelines on diabetes, pre-diabetes, and cardiovascular diseases developed in collaboration with the EASD. Eur Heart J 2020;41:255-323.

29. Rhee EJ, Kim HC, Kim JH, Lee EY, Kim BJ, Kim EM, et al. 2018 Guidelines for the management of dyslipidemia. Korean J Intern Med 2019;34:723-71.

30. Korean Diabetes Association. 2019 Treatment guidelines for diabetes [Internet]. Seoul (KR): Korean Diabetes Association; c2011 [cited 2020 Aug 24]. Available from: https:// www.diabetes.or.kr/pro/publish/guide.php?code=guide\&mode=view\&number=735. 